\title{
PELATIHAN PEMOGRAMAN PLC PADA SMKN 1 DI CILEUNGSI
}

\author{
Darwin, ST., M.Kom. Syaprudin, ST., M.Kom. Endang Saepudin, Dipl.Eng., M.Kom
}

\begin{abstract}
ABSTRAK
Kegiatan Pengabdian Kepada Masyarakat sebagai salah satu Tri Dharma Perguruan Tinggi ini bertujuan tersedianya perangkat praktik pemograman PLC dan sarana penunjang lainnya di Sekolah Menengah Kejuruan Negeri 1 Cileungsi Bogor. Salah satu program keahlian yang terdapat di sekolah ini adalah Program Keahlian Otomasi. Tujuan Kompetensi Keahlian teknik Otomasi secara umum mengacu pada isi undangUndang Sistem Pendidikan Nasional (UU SPN) pasal 3 mengenai Tujuan Pendidikan Nasional dan penjelasan pasal 15 yang menyebutkan bahwa pendidikan kejuruan merupakan pendidikan menengah yang mempersiapkan peserta didik terutama untuk bekerja dalam bidang tertentu. Dengan tersedianya sarana praktik Pemograman PLC di SMK Negeri 1 Cileungsi, banyak manfaat yang dapat diperoleh terutama dalam meningkatkan kompetensi siswa Program Keahlian Teknik Otomasi. Diantara kompetensi dasar adalah Pemograman PLC. Dengan adanya pelatihan ini diharapkan siswa dapat mempraktikkan merancang bangun teknik Otomasi dengan menggunakan PLC sehingga dapat menjadi warga negara yang kompetitif, produktif, adaptif, selektif, dan kreatif.

Human Machine Interface (HMI) merupakan perangkat antarmuka antar pengguna dengan sistem kendali. Dengan perangkat ini suatu sistem dapat dimonitor, diatur, dan diambil datanya sesuai kebutuhan pengguna. Pada Pengabdian Masyarakat ini dibuatlah sebuah modul latih PLC dan HMI yang menggunakan perangkat HMI Touchscreen Weintek MT8070IH5. HMI Touchscreen berfungsi untuk memonitor, mengoperasikan dan mengontrol mesin atau proses di suatu plant dengan layar sentuh. Pada perangkat tersebut diatur sejalan dengan Proggramable Logic Controller (PLC) sehingga menghasilkan suatu sistem yang dapat dimonitor dan diatur secara baik. Untuk membuat perangkat ini bekerja secara bersama-sama perlu dilakukan pengaturan komunikasi pada alat dan dihubungkan oleh Ethernet.
\end{abstract}

Kata Kunci : PLC

\section{PENDAHULUAN.}

Pengabdian pada Masyarakat merupakan salah satu refleksi tridharma Perguruan Tinggi yang dilaksanakan oleh Program Studi Elektrinika Industri. Setiap tahun telah melaksanakan Kegiatan Pengabdian Masyarakat berbasis Program Studi. Kegiatan ini diikuti baik oleh seluruh dosen tetap Elektronika Industri, dan mahasiswa/i yang ditunjuk oleh panitia dan tenaga kependidikan.

Mengacu pada program Polytechnic Education Development Project, PNJ, maka kegiatan Pengabdian kepada Masyarakat tahun ini dipilih tema Pelatihan Sistem
Integrasi PLC pada SMK di Cileungsi. Pelatihan ini dilaksanakan sebagai upaya pengenalan dasar sistem integrasi PLC pada tingkat SMK.

Untuk memenuhi kebutuhan industri pada bidang Elektronika Industri menyelenggarakan program pendidikan regular, merupakan pendidikan lanjutan dari SMA, MAN, dan SMK (sebidang) dengan lama pendidikan adalah 3 tahun yang dibagi menjadi 6 paket semester. Lulusan PS. EI berada pada Level-6 (Teknisi Ahli) dari Kerangka Kualifikasi Nasional Indonesia (KKNI), dengan kualifikasi mampu memanfaatkan IPTEKS dalam 
bidang instrumentasi dan kontrol di industri, serta mampu beradaptasi terhadap situasi yang dihadapi dalam penyelesaian masalah; menguasai konsep teoritis bidang otomasi industri secara umum dan konsep teoritis bidang instrumentasi dan kontrol industri secara mendalam, serta mampu memformulasikan penyelesaian masalah secara prosedural; mampu mengambil keputusan strategis berdasarkan analisis informasi dan data serta memberikan petunjuk dalam memilih berbagai alternatif; bertanggung jawab pada pekerjaan sendiri dan dapat diberi tanggung jawab atas pencapaian hasil kerja organisasi.

Jumlah SMK pada bidang elektronika industri di Cileungsi sangat terbatas. Kondisi ini menjadikan dasar tujuan dilaksanakannya pengabdian masyarakat berbasis program studi. Upaya PS D3 Elektronika Industri untuk meningkatkan pada bidang pemrograman PLC dan mencari calon mahasiswa baru dengan bibit yang lebih baik.

dilakukan diantaranya; melakukan studi pustaka, mencari literatur yang berkaiatan dengan sistem kerja alat, melakukan pengamatan dan tinjauan teknis terhadap produk sejenis

\section{Programmable Logic Controller (PLC)}

PLC merupakan suatu alat kontrol mikroprosessor serbaguna yang khusus dirancang untuk dapat beroperasi di lingkungan industri yang cukup besar. PLC bekerja dengan cara menerima data dari peralatan-peralatan input yang biasanya dapat berupa saklar, tombol-tombol, sensor-sensor dan lain-lain.

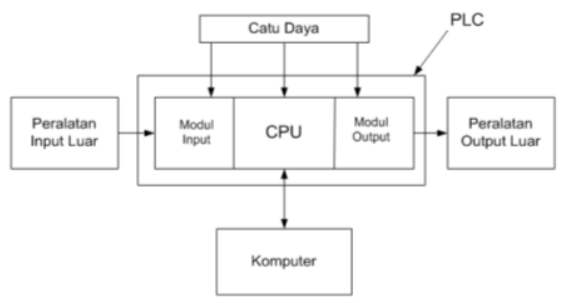

Gambar.1 Blok Diagram Sistem Pemograman PLC
Pada blok diagram sistem pemograman PLC gambar 1 dapat dijelaskan prinsip kerja dasar PLC yaitu program yang dibuat dalam bahasa ladder terlebih dahulu dirancang dalam computer dan didownload ke dalam PLC dengan

\section{Sistem Komunikasi}

Sistem komunikasi diperlukan untuk menghubungkan antara field device, PLC, dan Master Terminal Unit. Berikut ini beberapa sistem komunikasi yang dipakai dalam sistem

- $\mathrm{RS} 232$

- Private Network (LAN/RS-485)

- Communication PLC

- Switched Telephone Network

- Leased lines

- Internet

- Wireless Communication systems

- Wireless LAN

- GSM Network

- Radio modems

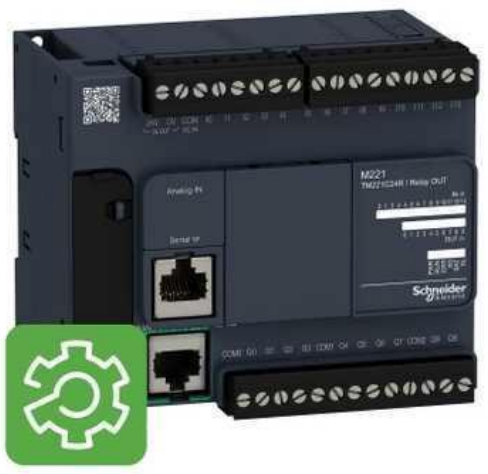

Gambar 2 PLC TM221ME16R

PLC mempunyai input output yang meliputi switch push button sebagai tombol mulai dan berhenti, aktuator valve, stepper motor, inductive proximity sensor sebagai sensor air penuh, buzzer sebagai alarm, dan LED yang digunakan sebagai representasi lampu on/off.

HMI (Human Machine Interface) touch panel digunakan untuk memonitor seluruh sistem kendali yang sedang berjalan baik dari input maupun output dengan akurat. Pada HMI Touch panel berbentuk simpel karna tanpa keybord dan mouse serta 
bentuknya yang relative kecil di banding sebuah monitor PC sehingga bisa di letakan menyatu pada panel kendali. HMI Touch Panel akan menampilkan seluruh bentuk animasi di layar sentuh dalam bentuk objek seperti aslinya di sistem kendali, misalkan ketinggian air, indikator lampu, gerakan, angka analog, tangki - tangki, pipa, pompa motor dan tombol-tombol.

Monitor HMI Touch Panel merupakan alat yang ideal untuk setiap industri, produksi atau lingkungan manufaktur. Permukaan HMI Touch Panel memiliki lapisan logam transparan yang bila disentuh menutup sebuah sirkuit listrik, memicu Graphical User perangkat lunak antarmuka atau HMI yaitu perangkat lunak yang mengakui posisi pada layar tersebut.

Fungsi dari HMI Touch Panel pada panel kontrol di industri adalah sebagai berikut :

1. Data processing, yaitu proses penerimaan data dari peralatan dilapangan, untuk dilaporkan kepada operator.

2. Supervisory control dimana memungkinkan operator untuk melakukan pengendali pada peralatan dilapangan.

3. Monitoring control dimana tempat memonitor seluruh sistem yang terdapat pada panel kontrol tersebut..

4. Tangging memungkinkan operator untuk menyampaikan informasi tertentu pada peralatan tertentu.

5. Post mortem review, yang membantu menentukan akibat pada sistem jika ada gangguan besar pada sistem.

6. Proses alarm dan event yang menginformasikan apabila terjadi perubahan pada sistem.

Pada pelatihan ini, HMI Touch Panel yang akan digunakan adalah MT8071IP merek dari WEINVIEW, dan untuk merancang desain HMI, digunakan software EasyBuilder. Sama halnya dengan software PLC, software HMI ini hanya bisa digunakan untuk merek WEINVIEW juga. Jika ingin merancang HMI dengan merek yang berbeda, maka programmer harus menginstal software HMI untuk merek tersebut.

Untuk merancang tampilan pada Weintek digunakanlah Easy Builder8000. Berikut merupakan tata cara merancang pada Easy Builder8000 :Pada pelatihan ini, PLC yang digunakan adalah PLC Schneider PLC Modicon TM221M16R/G (Modbus TCP/IP) dan untuk komunikasinya adalah Ethernet. Pada tahap awal membuat project baru dan menentukan tipe HMI Weintek, tipe PLC dan komunikasi PLC (interface) seperti terlihat pada Gambar 3 berikut ini.

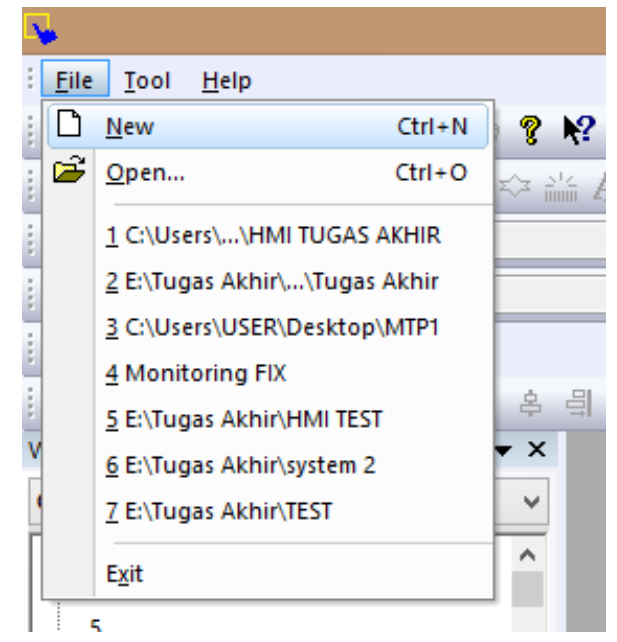

Gambar 3 Membuat Project baru

Selanjutnya adalah, memilih tipe HMI yang digunakan, yaitu tipe MT8071IP, seperti pada Gambar 4 berikut ini.

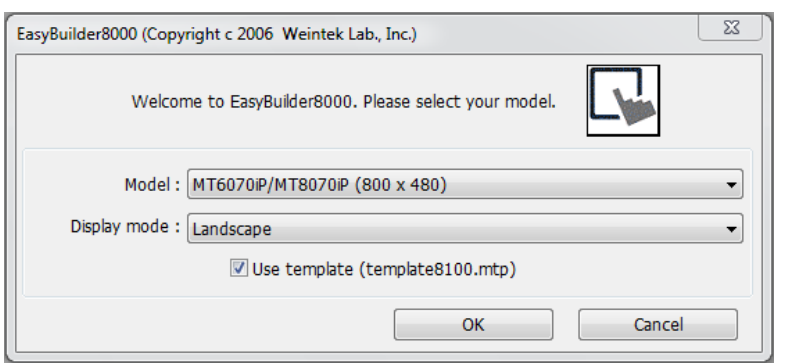

Gambar 4 Memilih Tipe HMI Weintek

Tahap berikutnya adalah dengan mengatur system parameter HMI dengan cara mengklik setting, seperti terlihat pada Gambar 5 berikut ini. 


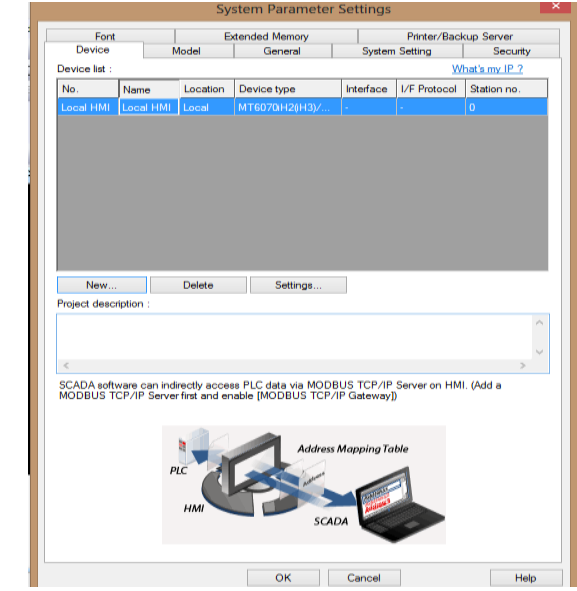

Gambar 5 Sistem Parameter

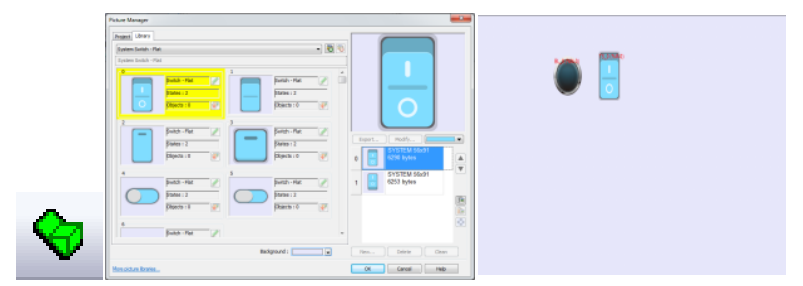

(a)

(b)

(c)

Gambar 6 a.Simbol Switch b.Pemilihan tipe switch c.Tampilan switch pada screen

\section{METODE PELAKSANAAN}

Metode Pelaksanaan Kegiatan Pengabdian kepada Masyarakat yang akan dilaksanakan sebagai berikut:

1. mengidentifikasi data SMK di Cileungsi dengan jurusan serumpun dan menentukan SMK yang akan dijadikan tempat tujuan Pengabdian pada Masyarakat.

2. Persiapan pembuatan dokumen, modul latih dan peralatan pendukung

3. Persiapan pelatihan mahasiswa dan mahasiswi PS D3 Elektronika Industri yang ditunjuk sebagai pemateri.

4. Pengadaan rangkaian modul latih sistem integrasi PLC dan peralatan pendukung

5. Perakitan rangkaian PLC dan peralatan pendukung

6. Pembuatan dokumen pelatihan

7. Pembuatan dokumen laporan kegiatan PengMas

\section{Prosedur Kerja}

Agar program kerja pengabdian masyarakat berjalan sesuai prosedur dibentuk tim kerja sebagai berikut:

\section{A. Tim Persiapan}

Tim Persiapan mempunyai tugas:

1. Melakukan koordinasi distribusi tugas setiap tim Prodi.

2. Melakukan koordinasi dan memilih kelompok masyarakat sebagai mitra kegiatan.

3. Melakukan koordinasi dengan pimpinan atau Kepala Sekolah penelitian dan mitra kegiatan pengabdian masyarakat.

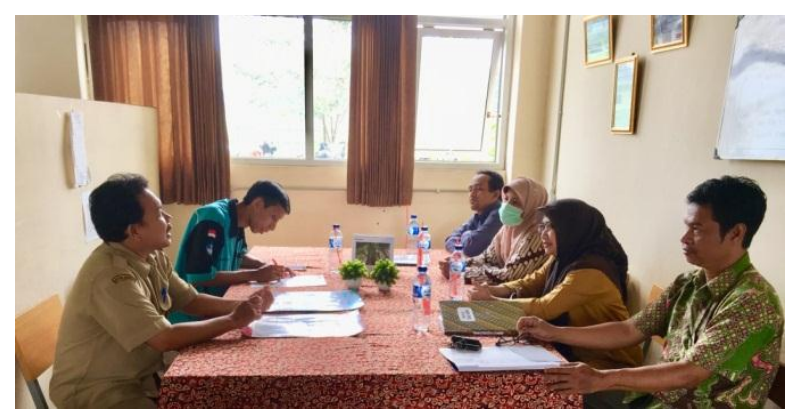

Gambar 7 Tim panitia melakukan koordinasi dengan Pimpinan SMK N 1 Cileungsi

4. Membuat penjadwalan kegiatan pemberian bantuan dan pelatihan sistem pengaturan sekuensial otomasi industri.

B. Tim Bimbingan dan Pemberi Pelatihan Sistem Pengaturan Sekuensial

Tim pemberi pelatihan dan bimbingan teknis mempunyai tugas:

1. Melakukan koordinasi dengan Kepala Sekolah dan guru-guru untuk diadakan acara pelatihan.

2. Secara simbolik perangkat dan modul latih diserahkan kepada Kepala Sekolah.

3. Menyediakan tenaga pelatihan penggunaan modul latih

4. Membuat kepanitiaan kegiatan pelatihan

5. Menyiapkan kuisioner dan mendistribusikan. 


\section{Persiapan Pelaksanaan}

1. Perakitan perangkat sistem HMI-PLC. Persiapan awal dari kegiatan pengabdian masyarakat ini adalah mempersiapkan perangkat modul latih sistem HMI-PLC yang akan digunakan pada saat pelatihan kepada Sekolah Menengah Kejuruan Negeri 1 Cileungsi. Seluruh komponen dibeli, dirakit, dan juga dimodifikasi agar mudah digunakan dan juga dapat beroperasi untuk perangkat komputer di sekolah tersebut.

2. Membuat rencana kegiatan pelaksanaan pengabdian masyarakat di SMK Negeri 1 Cileungsi.

Pelaksanaan kegiatan harus disusun secara rapi, agar tidak ada kendala teknis disana. Rencana tersebut meliputi; jadwal acara pelaksanaan penyuluhan dan serah terima perangkat modul latih sistem HMI-PLC kepada sekolah tersebut, daftar hadir guru yang diundang, pimpinan sekolah, pihak dosen dan mahasiswa dari PS D-3 Elektronika Industri. Serta serangkaian kegiatan pelaksanakan pengabdian masyarakat dari keberangkatan sampai kembali ke kampus.

3. Mempersiapkan bahan-bahan pengabdian, peralatan penunjang, dokumentasi.

Hal ini dimaksudkan agar peralatan penunjang, bahan-bahan, dan kesiapan konsumsi selama pelaksanaan pengabdian agar dapat diinventarisir dengan lengkap, dan juga memastikan peserta yang akan berangkat ke SMK tujuan.

\section{b). Pelaksanaan Pengabdian Masyarakat}

Pelaksanaan kegiatan Pengabdian Masyarakat kepada siswa dan guru di lingkungan SMK Negeri 1 Cileungsi direncanakan sebagai berikut :

1. Acara pertama setelah sampai dilokasi pengabdian, maka tim menemui kepala sekolah atau perwakilan pimpinan sekolah tersebut untuk perizinan dan silaturahmi. Dan juga koordinasi acara pengabdian masyarakat.
2. Setelah jadwal acara seremonial terbentuk, maka tim menunggu acara tersebut di tempat yang telah disediakan.

3. Acara berikutnya yaitu pelatihan sistem pengaturan sekuensial kepada kepala sekolah dengan seremonial dan disaksikan oleh pihak guru-guru dan siswa -siswi maupun para undangan.

4. Pihak PS D-3 Elektronika Industri dan Pihak SMK Negeri 1 Cileungsi masingmasing memberi sambutan dan harapanharapan bagi kemajuan pengabdian masyarakat dimasa yang akan datang.

5. Acara selanjutnya yaitu ramah tamah dan diskusi, mengenai langkah selanjutnya untuk kelanjutan pengabdian masyarakat ditahun mendatang. Dengan demikian didapat pemahaman dan MoU untuk kerjasama yang berkelanjutan.

Berikut ini adalah langkah-langkah kegiatan pengabdian masyarakat berbasis program studi yang telah dibagi dalam beberapa tahap dengan dilengkapi metode sebagai berikut :

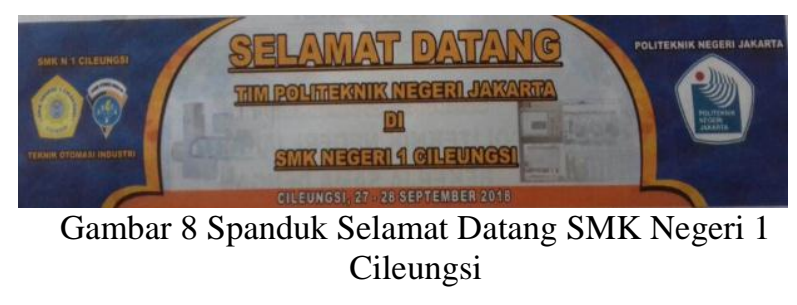

\section{A. Hasil}

Kegiatan pengabdian kepada masyarakat berbasis Program Studi Elektronika Industri telah dilaksanakan sesuai perencanaan. Kegiatan Pengabdian pada Masyarakat dengan mengadakan Pelatihan ke Sekolah Menengah Kejuruan yaitu SMK Negeri 1 Cileungsi, Kecamatan Cileungsi, Kabupaten Bogor, Provinsi Jawa Barat.

Bentuk kegiatan pengabdian pada masyarakat berupa pelatihan sistem pengaturan sekuensial yang saat ini sangat dibutuhkan oleh industri bidang otomasi industri berikut pemberian perangkat berupa modul latih PLC yang dapat digunakan sebagai media pembelajaran bagi SMK Negeri 1 Cileungsi. 


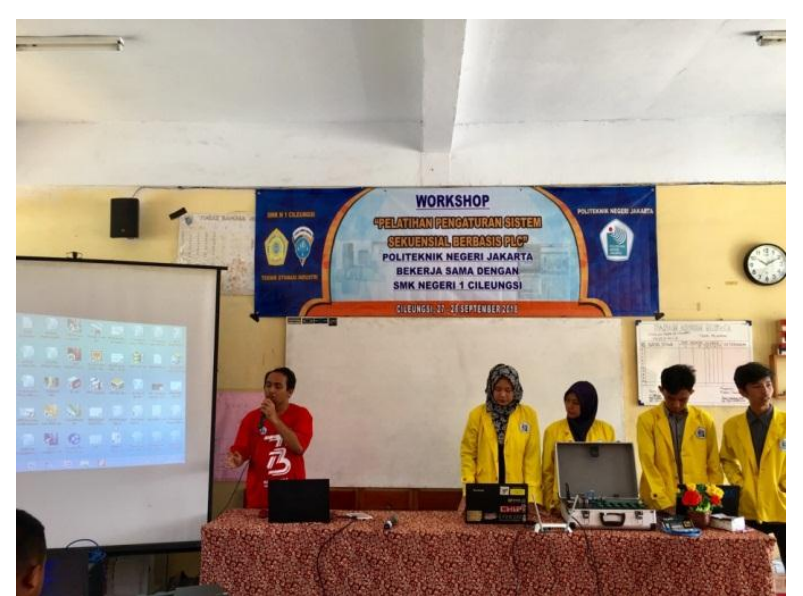

Gambar 9 Pelaksanaan Kegiatan Pengabdian pada Masyarakat di SMK Negeri 1 Cileungsi

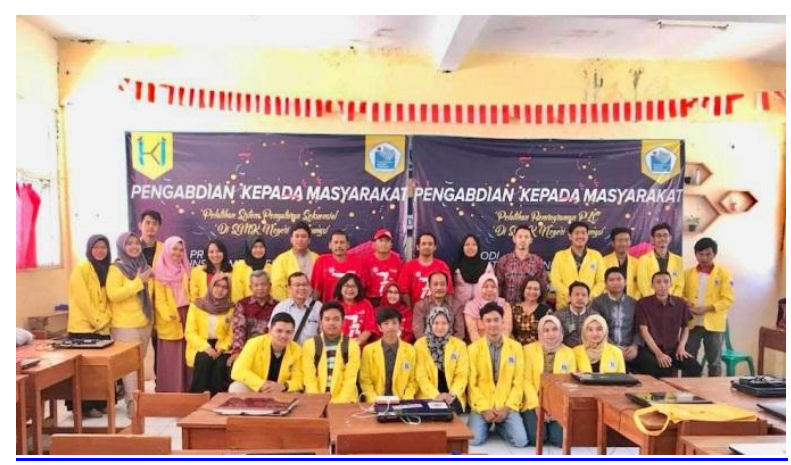

Gambar 10 Panitia Pengabdian Masyarakat berbasis Program Studi Elektronika Industri

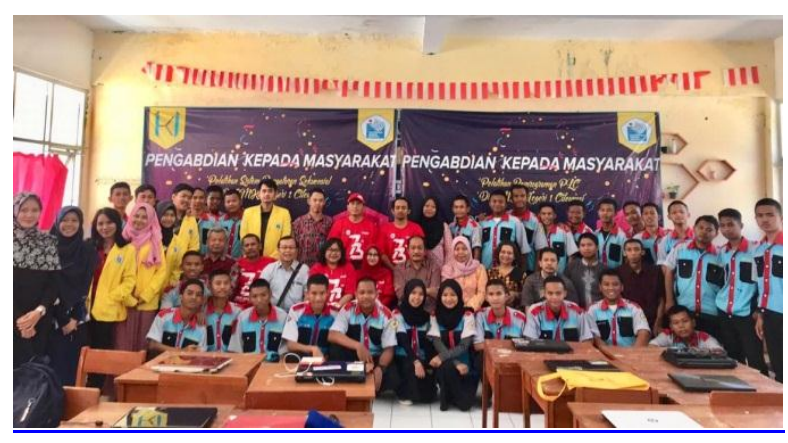

Gambar 11 Peserta Pelatihan siswa SMK Negeri I Cileungsi

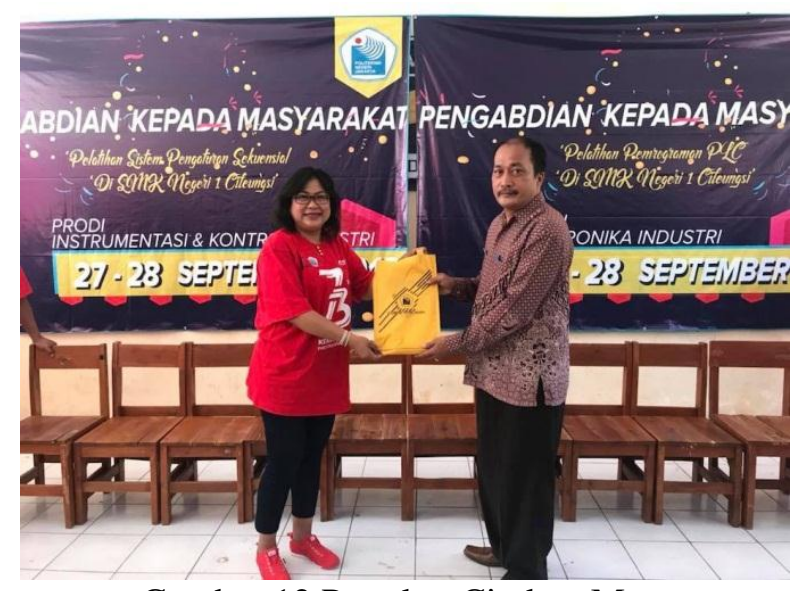

Gambar 12 Pertukar Cindera Mata

Kegiatan hari pertama dilaksanakan tanggal 27 September 2018, yang terbagi menjadi dua sesi yaitu pelatihan system integrasi berbasis PLC dan workshop system integrasi PLC. Kegiatan ini dibuka oleh Bapak Drs Syafrizal didampingi oleh Kepala SMK N 1 Cileungsi.

\section{DAFTAR PUSTAKA}

[1]

http://www.beritasatu.com/iptek/402217-

teknologi-otomatisasi-akan-berkembang-

di-ri.html

[2]

https://kotabogor.go.id/index.php/page/det

ail/9/letak-geografis

diakses tanggal 18 maret 2018.

[3] https://www.smkn1cileungsi.sch.id 